STUDI

FRANCESI

\section{Studi Francesi}

Rivista quadrimestrale fondata da Franco Simone

194 (LXV | II) | 2021

Baudelaire et son cénacle

\title{
OLIVIER PÉDEFLOUS, La dernière bibliothèque de Nicolas Bérauld. Livres et sociabilités lettrées dans les années 1530
}

\section{Filippo Fassina}

\section{(2) OpenEdition}

\section{Journals}

\section{Edizione digitale}

URL: https://journals.openedition.org/studifrancesi/44888

DOI: 10.4000/studifrancesi.44888

ISSN: 2421-5856

\section{Editore}

Rosenberg \& Sellier

\section{Edizione cartacea}

Data di pubblicazione: 1 août 2021

Paginazione: $360-361$

ISSN: 0039-2944

\section{Notizia bibliografica digitale}

Filippo Fassina, «olivier PÉdeflous, La dernière bibliothèque de Nicolas Bérauld. Livres et sociabilités lettrées dans les années 1530», Studi Francesi [Online], 194 (LXV | II) | 2021, online dal 01 septembre 2021, consultato il 15 octobre 2022. URL: http://journals.openedition.org/studifrancesi/44888 ; DOI: https:// doi.org/10.4000/studifrancesi.44888

Questo documento è stato generato automaticamente il 15 octobre 2022

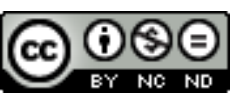

Creative Commons - Attribuzione - Non commerciale - Non opere derivate 4.0 Internazionale - CC BYNC-ND 4.0

https://creativecommons.org/licenses/by-nc-nd/4.0/ 


\section{OLIVIER PÉDEFLOUS, La dernière}

\section{bibliothèque de Nicolas Bérauld. Livres et sociabilités lettrées dans les années 1530}

Filippo Fassina

\section{NOTIZIA}

OLIVIER PÉDEFLOUS, La dernière bibliothèque de Nicolas Bérauld. Livres et sociabilités lettrées dans les années 1530, "Bibliothèque d'Humanisme et Renaissance" 2, LXXXI (2020), pp. 301-322.

1 Il presente studio intende ricostruire l'ultima biblioteca posseduta da Nicolas Bérauld negli anni successivi al 1530, al fine di sottolineare i rapporti di collaborazione e di amicizia con gli intellettuali contemporanei, in un periodo in cui Bérauld conduce una vita fondamentalmente nomade. È proprio seguendo i suoi viaggi che l'A. descrive i più importanti testi a lui appartenuti. In particolare, ci si sofferma su un volume di Aulo Gellio, ora conservato a Uppsala, che Bérauld avrebbe ottenuto da Jehan Lunel e che avrebbe utilizzato frequentemente per redigere il suo commento al Rusticus di Poliziano. Viene analizzato anche il periodo 1533-1534, nel quale Bérauld ha svolto un'intensa attività editoriale presso Sébastien Gryphe: vengono ricordate numerose opere redatte in questi anni, fra le quali spiccano l'Oratio de jurisprudentia e il Dialogue sur l'improvisation, in cui si trova una riflessione sulla scrittura improvvisata, sul modello di Quintiliano. Nel 1534 Bérauld torna a Orléans e acquista le Castigationes di Plinio: nell'ex libris di questo volume si trova per la prima e unica volta la formula «Et amicorum», che testimonia un importante sodalizio letterario nato attorno alla figura di Bérauld stesso. Vengono infine citati altri testi: un'edizione del De partu Virginis di Jacopo Sannazzaro, posseduta probabilmente anche da Dolet, poiché ne porta il timbro, 
e donata successivamente a Salmon Macrin e le opere complete di Ippocrate, che, secondo l'A., potrebbero essere state acquistate da Bérauld per cercare risposte ai suoi problemi di salute. La ricostruzione di questa biblioteca permette dunque di far luce sulle «sociabilités humaines» e sull'importante rete di rapporti fra intellettuali nell'area di Lione e Marsiglia negli anni trenta del Cinquecento. 